\title{
Research on Coordination Evaluation of Water Resources Utilization and Economic Development in Beijing
}

\author{
Dan $\mathrm{Wu}^{1, *}$ Yue $\mathrm{Li}^{1}$ Renxing Yang ${ }^{1}$ Yanlai Jin ${ }^{1}$ \\ ${ }^{1}$ School of Economics and Management, North China University of Technology, Beijing 100144, China \\ *Corresponding author.Email:wu_daniel@163.com
}

\begin{abstract}
The coordination degree evaluation method is used to evaluate the coordination degree of industrial water utilization structure and industrial structure in Beijing. On this basis, it is suggested to design the evaluation index system for the coordination of water resources utilization and economic development in Beijing, and the grey correlation analysis method and coordination degree evaluation method are used to evaluate the correlation degree and coordination degree between the utilization of water resources and economic development in Beijing. According to the research, it is found that during the period from the "Eighth Five-Year Plan" to "Thirteenth Five-Year Plan", the extensive degree of industrial water utilization structure in Beijing has shown a significant decline, from 0.71 to 0.36 ; the partiality to high water consumption in Beijing has a slight fluctuation and decline, from 0.29 to 0.09 ; and the coordination degree between industrial water utilization structure and the industrial structure in China has increased from 0.54 to 0.82 , changing from a "comparatively coordinated" state to a "coordinated" state. The grey correlation degree between water resources utilization and economic development in Beijing has shown a slightly upward trend, from 0.59 to 0.89 . The coordination degree between water resources utilization and economic development in Beijing has a small fluctuation range, increasing from 0.83 to 0.87 .
\end{abstract}

Keywords: Beijing, Water utilization structure, Industrial structure, Coordination, Evaluation.

\section{INTRODUCTION}

As a strategic production factor, basic living resource, and guaranteed ecological resource, water resources provide an important guarantee for economic development, residents' lives, and environmental protection in Beijing. In the 14th Five-Year Plan, Beijing proposed to strengthen the strategic reserve of water resources in Beijing,

*Fund: 2021 Beijing University Student Innovation and Entrepreneurship Training Program - "Research on

Coordination Evaluation of Water Resources Utilization and Economic Development in Beijing"

(108051360021XN216/004); General Project of Beijing Natural Science Foundation - "Research on Bidirectional Optimization and Adaptation of Water Resources and Industrial Structure under the Coordinated Development of Beijing-Tianjin-Hebei" (9202005); Yuyou Talent Project of North China University of Technology "Research on the Evaluation System of BeijingTianjin-Hebei Region's Resource Energy Consumption Management Performance and Its Cooperative Governance Capability from the Perspective of Technological Innovation" (No. XN020035) strengthen water pollution control and water resources protection, and improve the level of intensive and safe use of water resources, in order to accelerate the transformation and upgrading of Beijing's economic and industrial structure, and effectively improve the coordination between water resources utilization and economic development in Beijing. To this end, it is suggested to carry out the study on the coordination evaluation of water resources utilization and economic development in Beijing, which is conducive to providing decisionmaking support for optimizing Beijing's water resources allocation and improving the coordination between Beijing's water resources utilization and economic development. According to the existing literature, on the basis of constructing a comprehensive evaluation index system for water resources utilization and economic development [13], scholars mainly use VAR model [4], regional Gini coefficient [5], coupling coordination degree 
model [6], [7] and decoupling evaluation model [8], [9], [10], [11], [12] and other models to evaluate the coordination degree between water resources utilization and economic development. Judging from the research results of the coordination evaluation of water resources utilization and economic development in Beijing, scholars have carried out a correlation analysis on water resources utilization and economic development [13], [14], [15], and determined the dynamic trend of industrial structure and water resources utilization structure [16], [17], and focused on the evaluation of the decoupling relationship between water resources utilization efficiency, water resources utilization and economic development in Beijing [6], [18], [19], [20], [21]. However, few scholars have carried out coordination evaluation studies on Beijing's water resources utilization and economic development in different planning periods. To this end, the coordination degree evaluation method and grey correlation analysis method are used to construct the coordination evaluation model of industrial water utilization structure and industrial structure, and the coordination evaluation model of water resources utilization and economic development. It is required to develop researches on the correlation degree and coordination degree between water resources utilization and economic development in Beijing.

\section{RESEARCH METHODS}

\subsection{Coordination Evaluation Model of Industrial Water Utilization Structure and Industrial Structure}

The coordination degree evaluation method is used to evaluate the coordination degree between the industrial water utilization structure and the industrial structure based on the calculation of the extensive degree of industrial water utilization structure and the partiality to high water consumption. The formula can be expressed as:

$$
\left\{\begin{array}{l}
H_{t}=1-\sqrt{P_{t} * C_{t}} \\
P_{t}=\frac{J * G D P_{t}-\sum_{j=1}^{J} G D P_{j t} * j}{(J-1) * G D P_{t}} \\
C_{t}=\frac{J * W_{t}-\sum_{j=1}^{J} W_{j t} * j}{(J-1) * W_{t}} \\
j=1,2,3 ; \quad J=3
\end{array}\right.
$$

$H_{t}$ refers to the coordination degree between industrial water utilization structure and industrial structure in $t$ period. $P_{t}$ is the partiality to high water consumption in $t$ period; $j$ is the positional value of $j$ industry. If the industrial water utilization efficiency of $j$ industry is lowest, the positional value will be 1 , and so on. $G D P_{j t}$ is the added value of $j$ industry in $t$ period. $J$ is the sum of industries. And $G D P_{t}$ is the gross regional production. ${ }^{C_{t}}$ is the extensive degree of industrial water utilization structure in $t$ period; ${ }^{W_{j t}}$ is the water resources utilization amount of $j$ industry in $t_{\text {period; }} W_{t}$ is the total utilization amount of water resources in $t$ period. (See "Table 1")

Table 1. Evaluation criteria for the coordination of industrial water utilization structure and industrial structure

\begin{tabular}{|c|c|c|c|c|}
\hline H-value & $(0,0.25]$ & $(0.25,0.5]$ & $(0.5,0.75]$ & $(0.75,0.1]$ \\
\hline evaluation criterion & incoordination & poor coordinated & good coordination & coordination \\
\hline
\end{tabular}




\subsection{Coordination Evaluation Model of Water Resources Utilization and Economic Development}

Based on the establishment of a coordinated evaluation model of industrial water use structure and industrial structure, the coordinated evaluation index system of water resources utilization and economic development is designed, and the grey relational analysis method and coordination degree evaluation method are used to construct a coordinated evaluation model of water resource utilization and economic development. (See "Table $2 ")$

Table 2. Evaluation index system for the coordination of water resources utilization and economic development

\begin{tabular}{|c|c|c|c|}
\hline $\begin{array}{l}\text { Evaluation } \\
\text { dimension }\end{array}$ & Evaluation index & Index unit & Index explanation \\
\hline \multirow{5}{*}{$\begin{array}{l}\text { Water } \\
\text { resources } \\
\text { utilization } \\
\text { index }\end{array}$} & Water utilization rate of the primary industry & $\%$ & $\begin{array}{l}\text { Reflecting the water utilization rate of the } \\
\text { primary industry }\end{array}$ \\
\hline & Water utilization rate of the tertiary industry & $\%$ & $\begin{array}{l}\text { Reflecting the water utilization rate of the } \\
\text { tertiary industry }\end{array}$ \\
\hline & The percentage of water for life & $\%$ & $\begin{array}{l}\text { Reflecting the percentage of water for } \\
\text { life }\end{array}$ \\
\hline & $\begin{array}{l}\text { The percentage of water utilization for } \\
\text { ecological environment }\end{array}$ & $\%$ & $\begin{array}{l}\text { Reflecting the percentage of water } \\
\text { utilization for ecological environment }\end{array}$ \\
\hline & $\begin{array}{l}\text { Water utilization structure ratio of secondary } \\
\text { industry to tertiary industry }\end{array}$ & - & $\begin{array}{l}\text { Reflecting the water utilization structure } \\
\text { ratio of secondary industry to tertiary } \\
\text { industry }\end{array}$ \\
\hline \multirow{11}{*}{$\begin{array}{l}\text { Indicator of } \\
\text { economic } \\
\text { development }\end{array}$} & Per capital GDP & $\begin{array}{l}\text { yuan/perso } \\
\mathrm{n}\end{array}$ & GDP per unit of population \\
\hline & $\begin{array}{l}\text { The ratio of output value of primary industry } \\
\text { to GDP }\end{array}$ & $\%$ & $\begin{array}{l}\text { Reflecting the proportion of the output } \\
\text { value of the first industry }\end{array}$ \\
\hline & $\begin{array}{l}\text { The ratio of output value of tertiary industry to } \\
\text { GDP }\end{array}$ & $\%$ & $\begin{array}{l}\text { Reflecting the proportion of the output } \\
\text { value of the secondary industry }\end{array}$ \\
\hline & $\begin{array}{l}\text { Structure ratio of secondary industry to } \\
\text { tertiary industry }\end{array}$ & - & $\begin{array}{l}\text { Reflecting the proportion of the output } \\
\text { value of the secondary industry to that of } \\
\text { the tertiary industry }\end{array}$ \\
\hline & Water utilization per ten thousand yuan GDP & $\begin{array}{l}\mathrm{m}^{3} / \text { ten } \\
\text { thousand } \\
\text { yuan }\end{array}$ & $\begin{array}{l}\text { Reflecting the water performance of } \\
\text { economic development }\end{array}$ \\
\hline & $\begin{array}{l}\text { Water utilization of added value of secondary } \\
\text { industry per } 10,000 \text { yuan }\end{array}$ & $\begin{array}{l}\mathrm{m}^{3} / \text { ten } \\
\text { thousand } \\
\text { yuan }\end{array}$ & $\begin{array}{l}\text { Reflecting the water utilization efficiency } \\
\text { of the secondary industry }\end{array}$ \\
\hline & $\begin{array}{l}\text { Water utilization of added value of the tertiary } \\
\text { industry per } 10,000 \text { yuan }\end{array}$ & $\begin{array}{l}\text { m3/ten } \\
\text { thousand } \\
\text { yuan }\end{array}$ & $\begin{array}{l}\text { Reflecting the water utilization efficiency } \\
\text { of the tertiary industry }\end{array}$ \\
\hline & $\begin{array}{l}\text { Waste discharge of added value of the } \\
\text { secondary industry per } 10,000 \text { yuan }\end{array}$ & $\begin{array}{l}\text { t/ten } \\
\text { thousand } \\
\text { yuan }\end{array}$ & $\begin{array}{l}\text { Reflecting the pollution performance of } \\
\text { the secondary industry }\end{array}$ \\
\hline & Water utilization per capita & $\mathrm{m}^{3} /$ person & $\begin{array}{l}\text { Reflecting the water utilization of } \\
\text { population per unit }\end{array}$ \\
\hline & Water utilization per unit irrigated area & $\mathrm{m}^{3} / \mathrm{mu}$ & $\begin{array}{l}\text { Reflecting the water utilization efficiency } \\
\text { of agricultural irrigation }\end{array}$ \\
\hline & Water utilization per capita within China & $\mathrm{m}^{3} /$ person & $\begin{array}{l}\text { Reflecting the residents' water utilization } \\
\text { efficiency }\end{array}$ \\
\hline
\end{tabular}

According to "Equation (1)", the grey correlation analysis method and the coordination degree evaluation method are used to evaluate the coordination degree of Beijing's water resources utilization and economic development in different periods, reflecting the coordination situation of
Beijing's water resources utilization and economic development in different periods. Firstly, the grey correlation analysis method is used to calculate the grey correlation degree between the order parameter index and ideal index collection in $t$ period. That is,

$R_{t}=\frac{1}{m} \sum_{j=1}^{m} r_{t j}=\frac{1}{m} \sum_{j=1}^{m} \frac{\min _{t} \min _{j}\left|y_{t j}-\max _{t=1}^{T}\left\{y_{t j}\right\}\right|+\rho \max _{t} \max _{j}\left|y_{t j}-\max _{t=1}^{T}\left\{y_{t j}\right\}\right|}{\left|y_{t j}-\max _{t=1}^{T}\left\{y_{t j}\right\}\right|+\rho \max _{t} \max _{j}\left|y_{t j}-\max _{t=1}^{T}\left\{y_{t j}\right\}\right|}$ 


$$
y_{t j}=\left\{\begin{aligned}
w_{j} \cdot \frac{c_{t j}}{T} & \text { Performance } \\
\max _{t=1}\left(c_{t j}\right) & \\
w_{j} \cdot \frac{\min _{t=1}^{T}\left(c_{t j}\right)}{c_{t j}} & \text { Cost indicator }
\end{aligned}\right.
$$

In the formula, $R_{t}$ is the grey correlation degree between the order parameter index and ideal index collection in $t$ period; ${ }^{r}{ }_{j}$ is the grey correlation degree of $j$ indicator between the order parameter index and ideal index collection in $t$ period; $y_{t j}$ shows the weighted index value after the order parameter index of ${ }^{j}$ is normalized in $t$ period; $c_{t j}$ is the targeted value of the order parameter index of $j_{\text {in }} t$ period; $\max \left\{y_{t j}\right\}$ is the ideal value of the order parameter index of $j, \rho$ is the resolution ratio. When valuing $\rho$, it is suggested to obey the follow principle. It is to set $\Delta=\frac{\sum_{t=1}^{T} \sum_{j=1}^{m}\left|y_{t j}-\max _{t=1}^{T}\left\{y_{t j}\right\}\right|}{T \times m}$, and $\Delta$ is the mean value of absolute value of all the differences, namely, $\varepsilon_{\Delta}=\Delta / \max _{t} \max _{j}\left|y_{t j}-\max _{t=1}^{T}\left\{y_{t j}\right\}\right|$. When if it is $\max _{t} \max _{j}\left|y_{t j}-\max _{t=1}^{T}\left\{y_{t j}\right\}\right|>3 \Delta$, it should be $\varepsilon_{\Delta} \leq \rho \leq 1.5 \varepsilon_{\Delta} \quad ; \quad$ and if it is $\max _{t} \max _{j}\left|y_{t j}-\max _{t=1}^{T}\left\{y_{t j}\right\}\right| \leq 3 \Delta$, it should be $\varepsilon_{\Delta} \leq \rho \leq 2 \varepsilon_{\Delta}$.

Secondly, the coordination degree evaluation method is used to evaluate the coordination degree between water resources utilization and economic development.

$C_{t}=\frac{R_{t 1} \cdot R_{t 2}}{\left[\frac{R_{t 1}+R_{t 2}}{2}\right]^{2}}$
(1)

In formula, $C_{t}$ is the coordination degree between water resources utilization and economic development in $t$ period. Among, $R_{t 1}$ and $R_{t 2}$ are the indicators of water resources utilization and economic development in ${ }^{t}$, respectively.

\section{COORDINATION EVALUATION OF INDUSTRIAL WATER UTILIZATION STRUCTURE AND INDUSTRIAL STRUCTURE IN BEIJING}

The water resources bulletin of Beijing does not list the water utilization of the first industry, the second industry and the tertiary industry separately. Among them, it only statistics agricultural water utilization data of the first industry; industrial water utilization does not include the water utilization data of construction industry of the second industry; the water utilization data of third industry is included in the domestic water utilization data. Therefore, the conversion coefficients of water utilization for the first industry and agriculture, secondary industry and industrial engineering, and the water utilization for residents' living in Tianjin are estimated by referring to the water utilization of the three industries in "the water resources bulletin of Tianjin". The three industrial water utilization and the domestic water utilization of residents in Beijing are deduced and estimated respectively according to the principle of equal proportion. Finally, the industrial water utilization structure of Beijing from 1990 to 2019 is calculated, including the extensive degree of industrial water utilization structure, the partiality to high water utilization of industrial structure, the coordination degree between industrial water utilization structure and industrial structure, as shown in "Figure 1". 


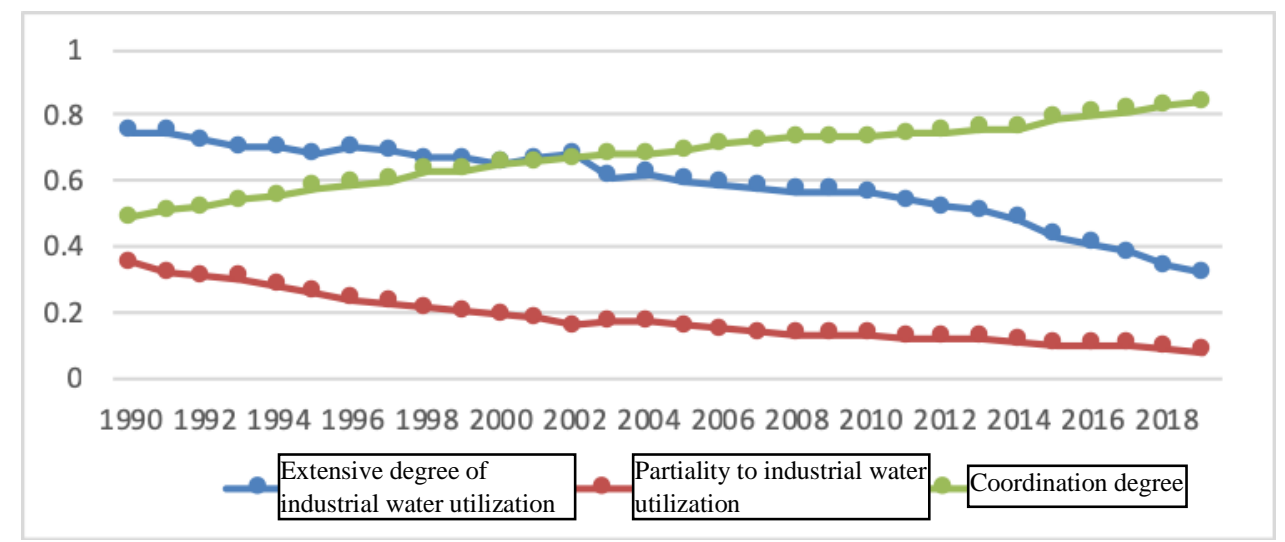

Figure 1 The coordination degree of industrial water utilization structure and industrial structure from 1990 to 2019.

According to "Figure 1", from 1990 to 2019, the extensive degree of industrial water utilization structure in Beijing showed a significant downward trend, from 0.75 in 1990 to 0.32 in 2019. The partiality to high water utilization of industrial structure in Beijing fluctuated slightly, from 0.35 in 1990 to 0.08 in 2019. Thus, it shows that the water utilization efficiency of Beijing is increasing and the industrial structure is optimizing. According to the evaluation criteria of the coordination degree between industrial water utilization structure and industrial structure in "Table 1", the evaluation results of the coordination degree between industrial water utilization structure and industrial structure in Beijing are as follows. In 1990, the industrial water utilization structure and industrial structure were in poor coordination, and the coordination degree was only 0.49 . From 1991 to 2011, the industrial water utilization structure and industrial structure were relatively coordinated, and the coordination degree continued to increase from 0.51 to 0.74 . From 2012 to 2019 , the industrial water utilization structure and industrial structure are in a state of coordination, and the degree of coordination continues to increase from 0.75 to 0.84. In general, during the period from "eighth five-year Plan" to "thirteenth five-year plan", the average extensive degree of industrial water utilization structure in Beijing decreased from 0.71 to 0.36 , the average partial degree of industrial structure decreased from 0.29 to 0.09 , and the average coordination degree of industrial water utilization structure and industrial structure increased from 0.54 to 0.82 , which changed from "relatively coordinated" state to "coordinated" state.

\section{EVALUATION OF \\ COORDINATION DEGREE BETWEEN WATER RESOURCES UTILIZATION AND ECONOMIC DEVELOPMENT IN BEIJING}

According to the evaluation indexes in "Table $2 "$, the grey correlation degree and coordination degree of water resources utilization and economic development in Beijing from 1990 to 2019 are calculated, as shown in "Figure 2". 


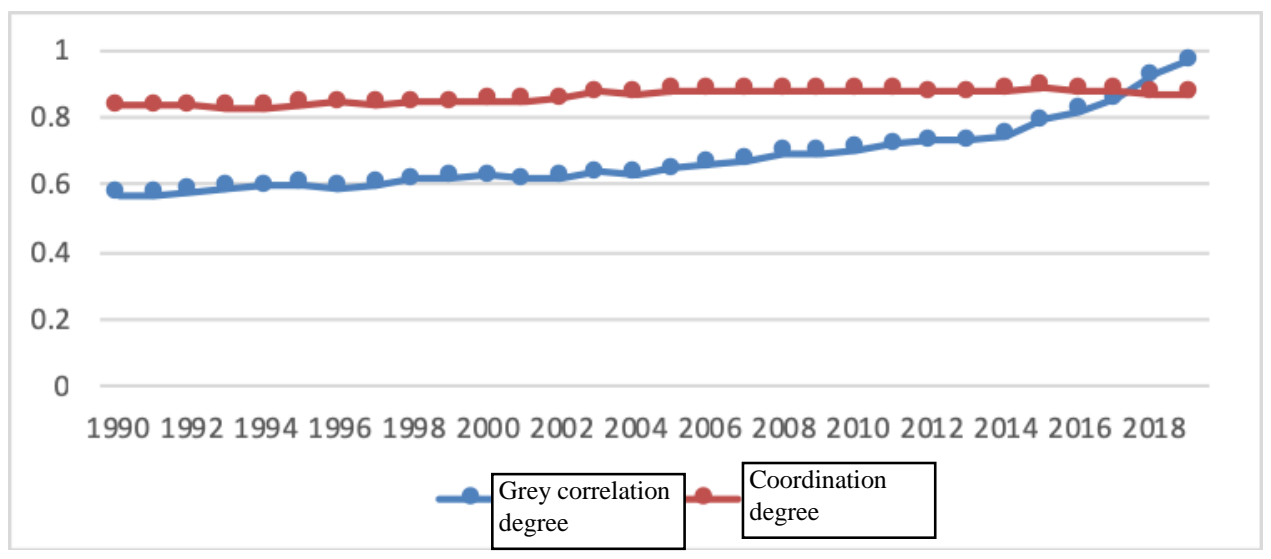

Figure 2 The grey correlation and coordination degree of water resource utilization and economic development from 1990 to 2019.

According to "Figure 2", from 1990 to 2019, the grey correlation degree between water resource utilization and economic development in Beijing only reached 0.57 in 1990. From 1990 to 2005, a small fluctuation rising trend can be seen, rising to 0.65 in 2005 and 0.70 in 2010 , exceeding 0.80 in 2016, and reaching 0.96 in 2019. From the perspective of the change of coordination between water resource utilization and economic development in Beijing, the coordination degree between water resource utilization and economic development is in the range of $[0.80,0.90]$, with a small fluctuation range and a slight increase, rising from 0.83 in 1990 to 0.87 in 2019 . In general, the grey correlation degree between water resource utilization and economic development in Beijing increased from 0.59 to 0.89 in the period from "eighth five-year Plan" to "13th five-year plan", and the average coordination degree between water resource utilization and economic development in Beijing increased from 0.83 to 0.87 .

\section{CONCLUSION}

From 1990 to 2019, the extensive degree of Beijing's industrial water utilization structure showed a significant decline, and the degree of partiality of Beijing's industrial structure showed a slight fluctuation and decline trend. From 1991 to 2011, the industrial water structure and industrial structure of Beijing were more coordinated. From 2012 to 2019, Beijing's industrial water utilization structure and industrial structure have been in a state of coordination. During the period from the "eighth five-year plan" to the "thirteenth five-year plan", the average value of the extensive degree between Beijing's industrial water utilization structure dropped from 0.71 to 0.36 . The average value of the partiality of Beijing's industrial structure dropped from 0.29 to 0.09 . As a result, it indicates that Beijing's water utilization efficiency is on the rise, and the industrial structure is continuously optimized. The average value of the coordination degree between the industrial water utilization structure and the industrial structure in Beijing increased from 0.54 to 0.82 , changing from a "comparatively coordinated" state to a "coordinated" state. From 1990 to 2019, the grey correlation between water resources utilization and economic development in Beijing showed a slight fluctuation upward trend, reaching 0.96 in 2019. The coordination degree between water resource utilization and economic development in Beijing has a relatively small fluctuation range, in the $[0.80$, 0.90], rising from 0.83 in 1990 to 0.87 in 2019 . During the period from the "eighth five-year plan" and "thirteenth five-year plan", the average grey correlation between water resource utilization and economic development in Beijing increased from 0.59 to 0.89 . The average value of coordination between water resource utilization and economic development in Beijing increased from 0.83 to 0.87 .

\section{AUTHORS' CONTRIBUTIONS}

Dan $\mathrm{Wu}$ is responsible for experimental design and writing the manuscript, Yue Li' Renxing Yang, Yanlai Jin is responsible for analysed data and writing the manuscript.

\section{REFERENCES}

[1] Gai Mei, Liu Leilei, Geng Yadong. Accordant Envelopment Evaluating Model of Dalian Water Resources and Social-economic and Its 
Application [J]. Resources Development and Market, 2011, 27(01): 56-59. (in Chinese)

[2] Gai Mei, Wang Yufei, Ma Guodong, et al. Evaluation of the Coupling Coordination Development between Water Use Efficiency and Economy in Liaoning Coastal Economic Belt [J]. Journal of Natural Resources, 2013, 28(12): 2081-2094. (in Chinese)

[3] Geng Fang, Dong Zengchuan, Guan Xike. The relationship between water use efficiency and economic development in Nanjing based on the coupling coordination degree model $[\mathrm{J}]$. Journal of Economics of Water Resources, 2017, 35(01): 21-25+76. (in Chinese)

[4] Deng Zhaohui, Liu Yang, Xue Huifeng. Study on the Dynamic Relationship Between Economic Growth and Water Resources-Use Based on the VAR Model [J]. China Population Resources and Environment, 2012, 22(06): 128-135. (in Chinese)

[5] Zhang Xiaotao, Yu Fawen. Analysis of the Matching Status Between Economic Development and Water Resources in the Yellow River Basin [J]. China Population-Resources and Environment, 2012, 22(10): 1-6. (in Chinese)

[6] Chang Ting, Jia Yucheng. Analysis on coordination degree of water resourceseconomy -society in Beijing-Tianjin-Hebei Region [J]. Yangtze River, 2020, 51(02): 9196. (in Chinese)

[7] Xing Xia, Xiu Changbai, Liu Yuchun. Research on Coupling and Coordination Relationship between Water Resources Utilization Efficiency and Economic Development [J]. Soft Science, 2020, 34(08): 44-50. (in Chinese)

[8] Pan An'e, Chen Li. Decoupling and Water Footprint Analysis of the Coordinated Development Between Water Utilization and the Economy in Hubei [J]. Resources Science, 2014, 36(02): 328-333. (in Chinese)

[9] Yang Renfa, Wang Taowu. Analysis of the decoupling of water resources utilization and economic coordinated development in Jiangxi Province - Based on the perspective of virtual water $[\mathrm{J}]$. Science and Technology Management Research, 2015, 35(20): 9598+111. (in Chinese)
[10] Liu Mingsheng, Liu Qingshan. Decoupling Analysis of Water Resources Utilization and Economic Coordinated Development Based on Water Footprint — Taking Guizhou Province as an example [J]. China Rural Water and Hydropower, 2017(08): 86-91. (in Chinese)

[11] Yang Jingxue, Hong Chuanchun. Analysis of the decoupling of water resources utilization and economic growth in the Beijing-TianjinHebei: based on the water footprint method [J]. Economic Perspective, 2018(05):27-35. (in Chinese)

[12] Qiao Yangyuan, Jia Chenzhong. Analysis of Water Resources Utilization and Economic Development in Shanxi Province Based on Water Footprint Theory [J]. Water Saving Irrigation, 2019(12). (in Chinese)

[13] Wu Dan, Wang Hongji, Liu Shuai. Analysis of the correlation between Beijing's economic development and water resources consumption and utilization $[\mathrm{J}]$. China Collective Economy, 2019(11):32-33. (in Chinese)

[14] Sun Yanzhi, Lu Chunxia, Xie Gaodi, et al. The conjunction between urban development and the utilization of water resources in Beijing [J]. Resources Science, 2015, 37(06): 1124-1132. (in Chinese)

[15] Wu Dan. Correlation analysis and bidirectional optimization model of industrial structure and water resources in BeijingTianjin-Hebei region [J]. China Population-Resources and Environment, 2018, 28(09): 158-166. (in Chinese)

[16] Liu Yang, Li Lijuan. The relationship between industrial structure and water consumption structure in Beijing-Tianjin-Hebei Region [J]. South-to-North Water Transfers and Water Science \& Technology, 2019, 17(02): 1-9. (in Chinese)

[17] Li Qingya, Pei Liang, Sun Liying, et al. Study on Temporal and Spatial Variation and Influencing Factors of Industrial Water Consumption in Beijing-Tianjin-Hebei Region [J]. Ecological Economy, 2020, 36(10):141145+159. (in Chinese)

[18] Wu Dan, Kang Xue. Evaluation of decoupling Beijing's economic development and water resources consumption and utilization [J]. 
China Collective Economy, 2019(14): 28-29. (in Chinese)

[19] Wu Dan, Xu Heyan. Evaluation on the Decoupling Trend and Efficiency of Water Resource Utilization of Economic Development in Beijing [J]. Technology and Industry, 2018,18(11): 33-38. (in Chinese)

[20] Yang Jingxue, Hong Chuanchun. Analysis of the decoupling of water resources utilization and economic growth in the Beijing-TianjinHebei region - Based on the water footprint method [J]. Economic Perspective, 2018(05):21-29. (in Chinese) [11]

[21] Jiang Boqian, Liu Xin. Evaluation on Efficiency of Water Utilization of Bohai Economic Zone Based on DEA-Malmquist [J]. Resources Development and Market, 2015, 31(01):49-51. (in Chinese) 